lately employed this means successfully in three very bad cases induces me to put on record the following brief notes on the subject as likely to be of some interest.

CASE 1.-A man about fifty-five years of age, suffering from melancholia with homicidal tendencies. Prolapsras recti occurred in March, 1892, and recurred frequently till the following July. Galvanism was applied soon after the bowel was replaced on the first occasion, and about once a week thereafter. After four montbs' treatment the bowel ceased to protrude, and between July, 1892, and May 13th, 1893, at which latter date the patient was sent to Ireland, no relapse occurred. He thus remained well for a period of at least ten months, and the tone of the sphincter seemed quite restored at the date of bis leaving the asylum.

CASE 2-A female chronic maniac fifty years of age. Prolapsus recti occurred in December, 1889. She concealed her condition at first, and when it was detected the protruded portion of gut was as large as a cricket ball and intensely congested and bleeding. The hernia could not be reduced till the patient was put thoroughly under chloroform. After the bowel was replaced the sphincter was so relaxed that five fingers could be easily inserted into it nearly as far as the proximal ends of the third phalanges. Galvanism was soon applied, but the bowel came down again frequently - in fact, almost every time that micturition was performed and every time that the bowels were evacuated. The cure was doubtless delayed by the obstinate conduct of the patient in concealing her condition every time a prolapse occurred; but after six months of galvanic treatment the bowel ceased to protrude, and the patient has now remained quite free from any return of the disorder for over three years and a half.

CASE 3.-A man thirty-two years of age. This patient was suffering from general paralysis of the insane and great impairment of the motor and ccördinating powers of the lower limbs. Obstinate constipation was a feature of the case. Prolapsus recti first occurred in December, 1892. Galvanism was applied frequently for six months without much apparent benefit; but after eight months' treatment the bowel seemed to have lost its tendency to come down, and now for four months the patient has been quite well in this respect. The state of the spinal cord constituted a very unfavourable element in the prognosis in this case.

Remarks.-Galvanism seems to have been saccessfully employed over thirty years ago in three cases of prolapsus ani, ${ }^{1}$ this is the only reference to the subject that I can find. In my cases an ordinary Smee's battery was employed. One pole was applied to the sphincter anj, the other pole to the spinous processes of the sacral and lumbar vertebræ, and the current made to pass for five minntes. This was repeated once or twice a week, whenever the bowel had to be replaced. The strength of the current was slight at first and gradually increased to nearly full strength. One disadvantage of this method of treatment is the long time required to effect a cure, but it must be admitted that more frequent applications might have been followed by more rapidly successful results. The classes of cases most suitable to treat in the way above noted are probably children and other restless patients, especially lunatics, who generally cannot be trusted to leave alone the wounds following an operation about the anus, and who are generally with the greatest difficulty prevented from tearing off dressings and bandages, or any retentive apparatus.

Rosslyn Castle, N.B.

\section{CIRCUMSCRIBED ATROPHY OF THE HAIR AND SKIN OF THE SCALP.}

\author{
BY TOM ROBINSON, M.D. ST. AND.
}

IT is not within the range of these few remarks to allude to the common form of bald patches which are met with in the hairy parts of the body. These are undoubtedly due to the invasion of the skin by a micro-organism, and they are known by the generic name of alopecia areata. But I am desirous to call attention to a groug of cases which, so far as I know, have not hitherto been described, and which are distinguished by the following attributes:-1. The atrophic areæ are confined to the scalp. 2. The areæ are

1 Medical and Chirurgical Review, vol. i., p. 106, 1859. absolutely bald. 3. The areæ are depressed like ordinary scars. 4. The hair never returns. The following case is an example of the condition.

A woman thirty-nine years of age, who has always had a fair share of health and who is the mother of six children. came to me in 1893 because "her hair was coming out." There was nothing unusual in her skin or epidermic strue tures, but on examination she had a cluster of bald patches on her scalp, which were practically confined to the parietal regions. They varied in size from a split pea to a shilling; some had joined at their circumference. I could not obtain a history of any inherited tendency towards the condition, and it may be taken as a fact that she had not been syphilised. Neither had she at any time been the subject of severe headaches or had any injury. The scars (for such they literally were) resembled those one sees when lupus erythematosus attacks the scalp or when a scald or a burn has been inflicted. I have looked carefully through my notes taken during the last ten years, and, altbough $I$ find that thirteen such cases have consulted me, in every instance the patient has been a woman. I have naturally asked myself the question, "Why do these patches occur?" and I confess to an inability to find a satisfactory reply. The medical man might shelter himself behind $a$ theory of local anæmia, which in the first degree would produce a diminished growth of hair, and if continued would lead to atrophy or even to local death, but no one would accept such a hypothesis. Cases of loss of hair which have been either a sequel or a symptom connected with profound disturbance of the nervous system are on record. Cooper Todd described the case of a man who fell from a waggon and sustained injuries which caused hemiplegia and loss of consciousness, and who one day on going to shave him. self could not find any beard. Fischer, who had great experience in military surgery, noticed after ganshot wounds that the limb corresponding to the wound received (if that wound had interfered with the nervous integrity of the part) became bald. Virchow describes a circumscribed atrophy which has been observed in one-half of the face, but at times in other parts of the body. On careful examination of the whole cutaneous area of an old man evidence of cutaneous wasting will usually be found occurring locally and generaliy, the skin being wanting in lustre, and in scme old and thin men I have seen the epidermis of the face and shins stretched over the bones like a piece of hog's bladder. Wilson called the condition derma toxerasia. Celsus, in his chapter de areis, describes a form of baldness which probably refers to the case now under discassion. It is what he calls the worst form-namely, that which destroys the fat and renders the surface totally smooth-but he confuses it obviously with alopecia areata One may without any unfair straining of theory easily under stand that the injurious and positively cruel way in which women produce the cuiling of the hair will account for an injury to the scalp. Curling pins, curling irons, and curling papers form an essential part of the toilet armoury of almost every woman, and this torturing of the hair drags on the roots, and by so doing starts the inflammation which may be the forerunner of this atrophy. The scalp being so dull of sensation will enable the victim to bear a good deal of tension without much suffering. Again, the number of hairpins used in dressing the head may damage the scalp.

Prince's-street, Cavendish-square, $\mathrm{w}$.

\section{RECOVERY FROM OVARIOTOMY: FIVE WEEKS SUBSEQUENTLY DEATH FROM CANCER OF THE PANCREAS AND DUODENUM.}

BY JOHN D. MALCOLM, M.D, C.M., F.R.C.S. EDIX SURGEON TO THE SAMARITAN FREE HOSPITAL.

A congenital deat-mute, single, forty-nine years of age consulted me on Feb. 23rd, 1892, on account of an enlarge. ment of the abdomen, which had been increasing for about five years, and yellowness of the skin, which had existed for three months. Emaciation had taken place, but not to any great extent until the last four or five months, during which time it had been very rapid, and the abdominal swelling had also increased more quickly. There had beer 